\section{COMMENT}

ATLL was first described as a distinctive malignancy of mature CD4+ (helper) T cells, when a high prevalence was reported in south-west Japan. It was subsequently identified in West Indian immigrants in the UK, and human T-cell leukaemia virus type-1 (HTLV-1) is now known to be the causative agent of ATLL ${ }^{1}$. Some 10-20 million people world-wide are infected with HTLV-1, which is endemic to Japan, the Caribbean, Central and South America and Africa where the seroprevalence is $1-20 \%$. The estimated lifetime risk of developing ATLL in a person positive for HTLV-1 is $2-5 \%$, with a latency of $20-30$ years.

ATLL occurs in adults, with a median age at onset of 58 years, and is classified into four clinical subtypessmouldering, chronic, lymphoma and acute. Patients with the first two subtypes rarely develop hypercalcaemia. Acute type ATLL is the commonest and both acute and lymphoma types have a much poorer prognosis than the other two subtypes. Poor prognosis is further indicated by raised LDH and calcium and by a high WBC, with 50\% survival of less than 6 months even with combination chemotherapy ${ }^{2}$. Treated with zidovudine and $\alpha$-interferon, a small percentage of patients achieve longlasting remission ${ }^{3}$.

The exact prevalence of HTLV-1 positivity is hard to assess, though the prevalence in Jamaicans over 70 has been estimated at $17.4 \%$ for women and $9.1 \%$ for men. The North London Blood Transfusion Service estimate a prevalence of $0.005 \%$ in their local blood donors, whilst a study of Afro-Caribbean blood donors suggested a prevalence of $0.1 \%{ }^{4}$. The catchment area of the Central Middlesex Hospital has a high immigrant population (approximately 45\% non-English origin). In a study from the Royal London Hospital, which also serves a large ethnic minority population, 12 cases of HTLV-1 associated disease were found over 5 years ${ }^{5}$.

Hypercalcaemia is a common finding in the normal population and in hospital patients ${ }^{6}$. The approach to investigation is reviewed elsewhere ${ }^{7}$. Hypercalcaemia occurs in about $50 \%$ of patients with HTLV-1 induced ATLL, and, as in the three cases presented, attempts to control calcium levels may dominate the clinical course. The mechanism of hypercalcaemia associated with ATLL seems to be stimulation of bone resorption by the production of parathyroid-hormone-related peptide (PTH$\mathrm{rP}$ ), with ATLL cells constitutively expressing a large amount of PTH-rP mRNA ${ }^{8}$.

\section{REFERENCES}

1 Yoshida M, Miyoshi I, Hinuma Y. Isolation and characterization of retrovirus from cell-lines of human adult $\mathrm{T}$-cell leukaemia and its implication in the disease. Proc Nat Acad Sci USA 1982;89:2031-5

2 Seigel R, Gartenhaus R, Kuzel T. HTLV-1 associated leukaemia/ lymphoma: epidemiology, biology and treatment. Cancer Treat Res 2001; 104:75-88

3 Gill PS, Harrington W Jr, Kaplan MH, et al. Treatment of adult T-cell leukemia-lymphoma with a combination of interferon alfa and zidovudine. N Engl J Med 1995;332:1744-8

4 Salker R, Tosswill JH, Barbara JA, et al. HTLV-I/II antibodies in UK blood donors. Lancet 1990;336:317

5 Hoque S, Kelsey S, van der Walt JD, Breuer J. Experience of human lymphotropic virus type 1 (HTLV-1) in an East London hospital. $J$ Infect 1996;32:33-9

6 Frolich A. Prevalence of hypercalcaemia in normal and hospital populations. Dan Med Bull 1998;45:436-9

7 Bushinsky DA, Monk RD. Calcium. Lancet 1998;352:306-11

8 Watanabe T, Yamaguchi K, Takatsuki K, Osame M, Yoshida M. Constitutive expression of parathyroid hormone-related protein gene in human T cell leukemia virus type 1 (HTLV-1) carriers and adult T-cell leukemia patients that can be trans-activated by HTLV-1 tax gene. J Exp Med 1990;172:759-65

\title{
Pathergy in non-Hodgkin lymphoma
}

\author{
Ikram A Burney Tariq Moatter ${ }^{1}$ \\ Tariq Siddiqui Nausheen Yaqoob ${ }^{1}$
}

J R Soc Med 2003;96:127-129

Pathergy is the development of a papulopustular lesion around a puncture site on the skin, $24-48$ hours after the injection of a sterile substance ${ }^{1}$. The pathergy test is used in some parts of the world as a diagnostic criterion for Behçet's disease ${ }^{2}$.

\section{CASE HISTORY}

A man aged 24 reported low-grade fever for eight months, pain and swelling in the right leg and knee for about six months and pustular lesions over the lips, arms and genitalia for the past three months. During this period he had been in Saudi Arabia and had been admitted three times for the treatment of fever and abscesses. Culture of aspirates from the right knee joint had been negative; $40 \%$ of the white cells were lymphocytes, $60 \%$ neutrophils; protein $53 \mathrm{~g} / \mathrm{L}$. On admission to our hospital he was febrile and tachycardic. There was no palpable lymphadenopathy. Over the left forearm and right elbow there were raised ulcers with

Departments of Medicine and ${ }^{1}$ Pathology, Aga Khan University, Stadium Road, PO Box 3500, Karachi 74800, Pakistan

Correspondence to: Dr Ikram A Burney

E-mail: ikram.burney@aku.edu 


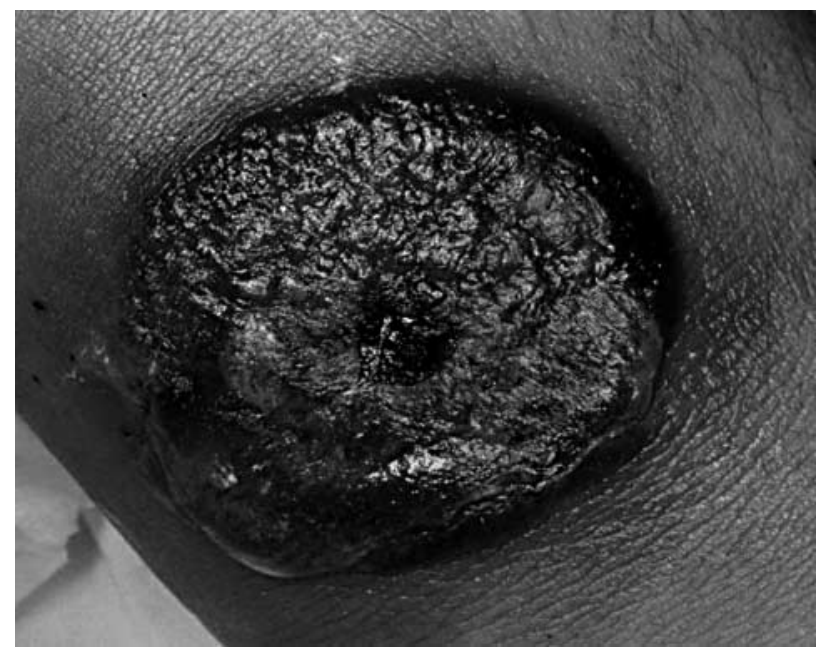

Figure 1 Lesion over forearm

undermining edges, exuding yellowish discharge; there were also multiple lesions on the lips and genitalia. Haemoglobin was $5.9 \mathrm{~g} / \mathrm{dL}$, white cell count $7.2 \times 10^{9} / \mathrm{L}$ (72\% neutrophils, 20\% lymphocytes, $2 \%$ eosinophils, $7 \%$ monocytes) and platelet count $43 \times 10^{9} / \mathrm{L}$. Renal function was within normal limits, but there was evidence of liver dysfunction in a serum albumin of $1.9 \mathrm{~g} / \mathrm{dL}$ and a prothrombin time of $19 \mathrm{~s}$ (control $12 \mathrm{~s}$ ); bilirubin, alanine aminotransferase and alkaline phosphatase were normal.
The patient was treated with cloxacillin, amikacin, ceftazidime and metronidazole but did not respond. During the first 48 hours new eruptions developed at the site of insertion of intravenous cannulae and venepunctures. Figure 1 shows the lesion over the forearm. The clinical diagnosis was Behçet's disease. Antinuclear factor, antismooth-muscle antibody and antimitochrondrial antibody were all negative, as was a test for human immunodeficiency virus infection. A bone marrow aspirate yielded only hypocellular marrow, but a bone trephine biopsy revealed diffuse fibrosis and stained positively with the reticulin stain. Also, there was an abnormal population of heterogeneous mononuclear cells. A lesion similar to the other lesion developed around the site of insertion of the Jamshidi needle. The presumptive diagnosis was then myelofibrosis with secondary pyoderma gangrenosum.

Figure $2 a$ shows the histopathology of the skin biopsy. A diffuse dense lymphocytic infiltrate is visible at the dermoepithelial junction and in the periadnexal and perivascular area. There were atypical lymphoid cells, which were focally infiltrating into the epidermis. The nuclei were pleomorphic and hyperchromatic. The neoplastic cells were also infiltrating the vessel wall. Both the skin lesion and bone biopsy were positive for leucocyte common antigen (LCA) and $\mathrm{T}$ cell surface markers (i.e. UCHLA1 and CD3) but were negative for CD20, a B-cell (a)

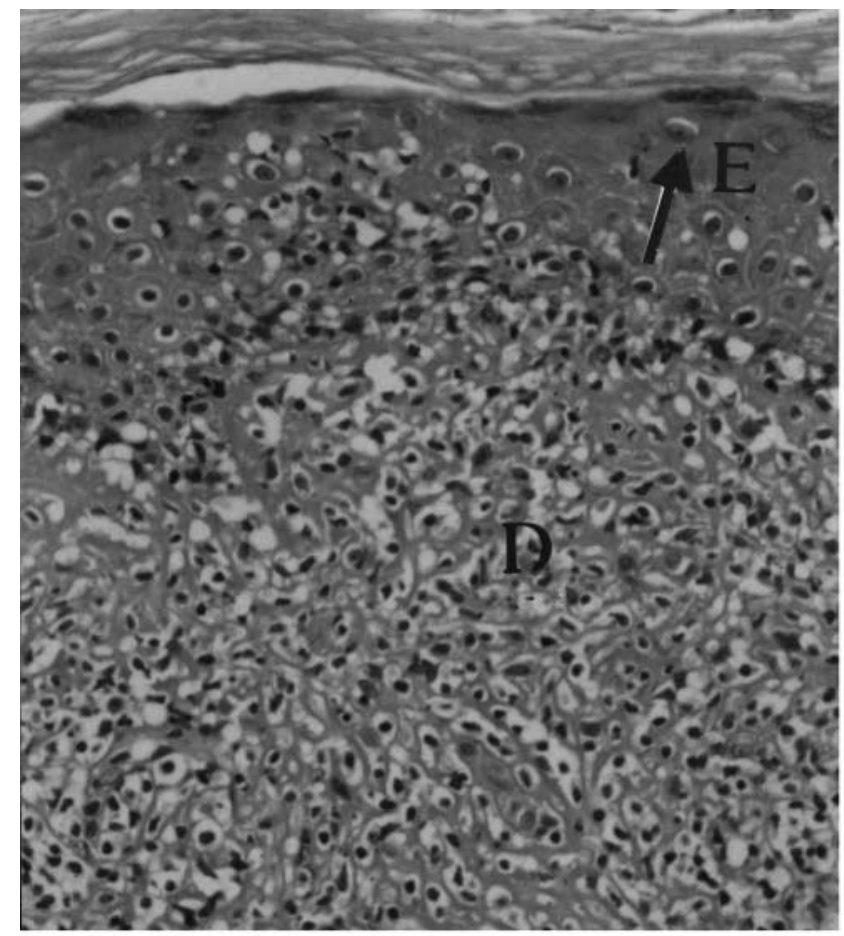

(b)

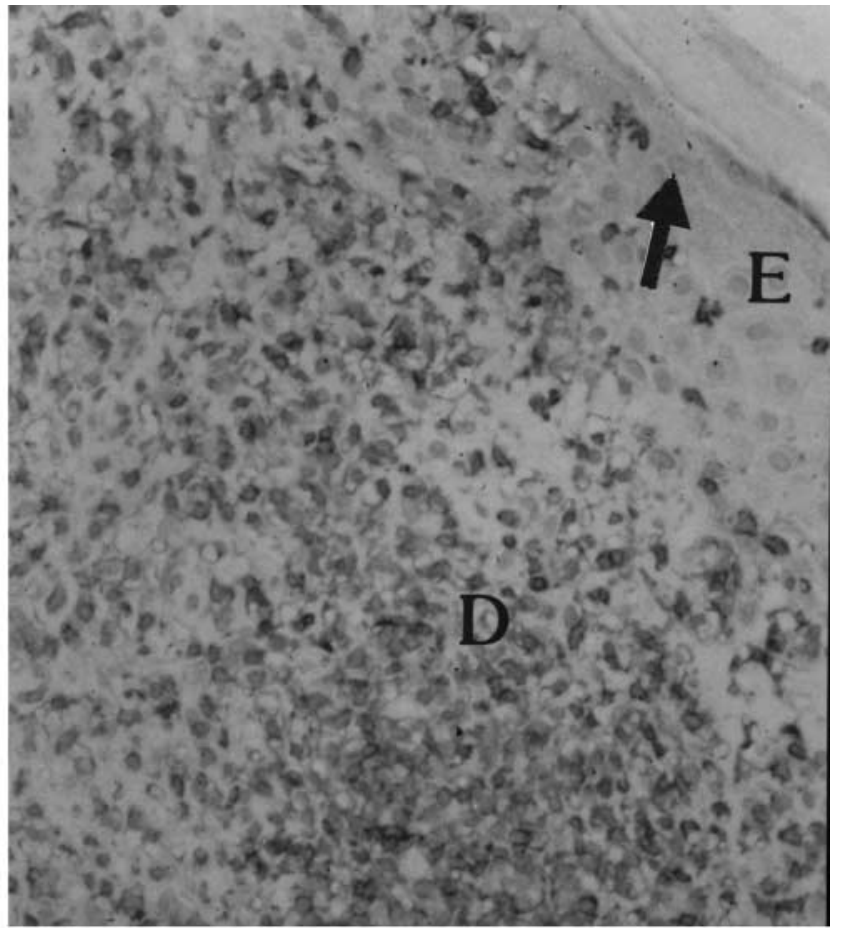

Figure 2 Photomicrograph of skin lesion. (a) Stained with haematoxylin and eosin ( $\times 20)$. Note dense dermal (D) infiltrate with focal epidermotropism (E) by atypical lymphoid cells (arrow). (b) Stained with a pan T (UCHL1) antibody ( $\times 40)$. Note strong labelling of atypical lymphoid cells 
marker (Figure 2b). Monoclonality at the DNA level in the $\mathrm{T}$ cell population was confirmed by $\mathrm{T}$ cell receptor $\gamma$ chain gene rearrangement assay. DNA was extracted from a formalin-fixed paraffin-embedded skin biopsy specimen by use of a Nucleon genomic DNA extraction kit (Nucleon Biosciences, USA). The polymerase chain reaction was performed as described by McCarthy et $a .^{3}$ on an automated thermal cycler (Perkin Elmer, Model 9600, USA).

The patient was diagnosed as having a non-Hodgkin lymphoma stage IV and was started on combination chemotherapy. He went into partial clinical remission after a month and was then referred to a centre near his home.

\section{COMMENT}

A positive pathergy test is one of the diagnostic criteria for Behçet's disease $^{2}$. The initial reaction to sterile puncture is a rapid accumulation of neutrophils along the needle track ${ }^{4}$. The neutrophils and the vascular endothelium are abnormally sticky ${ }^{5}$. The endothelial cells express ICAM-1 and E-selectin ${ }^{1}$. Rapid accumulation of neutrophils is followed by a sharp decline in their numbers, such that after $48 \mathrm{~h}$ they constitute only $5 \%$ of the infiltrating cells ${ }^{1,4}$. Hyperchemotaxis attracts a dense mononuclear cell infiltrate consisting predominantly of monocytes, macrophages, and CD4+ lymphocytes ${ }^{1}$. As well as in Behçet's disease, pathergy has been described in pyoderma gangrenosum, in hairy cell leukaemia and in chronic myeloid leukaemia treated with interferon alpha6,7. The lesions in our patient were characteristic of pathergy, but the final diagnosis was T-cell non-Hodgkin lymphoma. To our knowledge, this is the first such case presenting with a pathergy reaction.

\section{REFERENCES}

1 Gul A, Esin S, Dilsen N, Konice $\mathrm{M}$, Wigzell $\mathrm{H}$, Biberfeld $\mathrm{P}$. Immunohistology of skin pathergy reaction in Behçet's disease. $\mathrm{Br} J$ Dermatol 1995;132:901-7

2 International Study Group for Behçet's Disease. Criteria for diagnosis of Behçet's disease. Lancet 1990;335:1078-80

3 McCarthy KP, Sloane JP, Kabarowski HS, Matutes E, Weidemann LM. A simplified method of detection of clonal rearrangements of the T-cell receptor gamma chain gene. Diag Mol Pathol 1992;3:173-9

4 Djawari D, Hornstein OP, Luckner L. Skin window examination according to Rebuck and cutaneous pathergy tests in patients with Behçet's disease. Dermatologica 1985;170:265-70

5 Dwarakanath AD, Yu LG, Brookes C, Pryce D, Rhodes JM. Sticky neutrophils, pathergic arthritis, and response to heparin in pyoderma gangrenosum complicating ulcerative colitis. Gut 1995;37:585-8

6 Kaplan RP, Newman G, Saperia D. Pyoderma gangrenosum and hairy cell leukemia. J Dermatol Surg Oncol 1987;13:1029-31

7 Budak-Alpdogan T, Demircay, Alpdogan O, et al. Skin hyper-reactivity of Behçet's patients (Pathergy reaction) is also positive in interferon alpha-treated chronic myeloid leukemia patients indicating similarly altered neutrophil function in both disorders. $\mathrm{Br} J$ Rheumatol 1998;37:1148-51

\section{Three cases of atypical mycobacterial cervical adenitis}

\author{
Mary-Louise Montague MRCS \\ S S Musheer Hussain FRCS Robin L Blair FRCS
}

J R Soc Med 2003;96:129-131

Atypical mycobacterial cervical adenitis (AMCA) in children is a condition that still presents management dilemmas.

\section{CASE HISTORIES}

\section{Case 1}

A girl of 5 developed a persistent discharging sinus in the left submandibular region after an incomplete excision biopsy at another centre (Figure 1). At further operation the sinus and matted lymph nodes adherent to the internal jugular vein were removed with preservation of the lower cranial nerves. She was also treated with clarithromycin for three weeks preoperatively and three weeks postoperatively. Mycobacterium avium was cultured after eight weeks. The wound healed well, with good cosmetic outcome.

\section{Case 2}

An 8-year-old boy was referred with persistent left-sided cervical lymphadenopathy. He was otherwise well. There was no response to treatment with co-amoxiclav. AMCA was suspected and, after three weeks' treatment with clarithromycin and ciprofloxacin (which was continued for three weeks postoperatively), he underwent complete excision of affected glands. The final outcome was again good. Tissue cultures were negative after twelve weeks of incubation but special stains showing acid-fast bacilli, together with granulomatous inflammation on histological sections, lent strong support to the clinical diagnosis.

\section{Case 3}

A girl of 3 had a persistent cystic violaceous lump at the angle of the right mandible (Figure 2). After needle aspiration of the lump a persistent parotid salivary fistula developed. Slides prepared with special stains yielded acid-fast bacilli. There was no response to six weeks' dual

Department of Otolaryngology, Ninewells Hospital and Medical School, Dundee DD1 9SY, Scotland, UK

Correspondence to: S S Musheer Hussain

E-mail: s.s.musheer.hussain@tuht.scot.nhs.uk 